\title{
Effects of Horticultural Activities Designed to Stimulate Five Senses on the Sensory Development of Children
}

\author{
Hae Soon Yun, Suk Young Yun*, and Byung Jin Choi \\ Department of Horticultural Therapy, Daegu Catholic University, Gyeongsan 38430, South Korea
}

\begin{abstract}
The purpose of this study was to look into the effect of horticultural activities designed to stimulate five senses on a child's sensory development. This study selected 22 children at ' $\mathrm{H}$ ' child community center located in D city as research subjects, and conducted a program consisting of 12 sessions (once a week) from January 4 to March 29, 2017. Each session's horticultural activities were designed to stimulate all five senses in children. The research results are as follows: first, the control group didn't show any significance in changes of attention concentration by sense before/after implementing the program, but in case of the experimental group, all senses but a major hand tactile sense were found significantly improved. For visual sense assessments, selective attention was improved from 4.5 scale before implementing the horticultural activity to $7.6 \mathrm{scale}(p=.000)$; sustained attention was improved from 4.3 scale before implementing the activity to 7.8 scale after implementing the activity $(p=.000)$; self-control was improved from 4.3 scale before implementing the activity to 7.3 scale $(p=.000)$, and in case of tactile concentration, a non-major hand dexterity was enhanced from 29.6 seconds before implementing the activity to 23.2 seconds $(p=.000)$ after implementing the activity, but a major hand didn't show any significant change. In the measurement of auditory concentration, it was significantly improved from 9.4 score before implementing the activity to 12.2 score $(p=.001)$ after implementing the activity. Olfactory concentration was also significantly improved from 1.2 score before implementing the activity to $2.2 \mathrm{score}(p=.002)$ after implementing it. Taste concentration was also found improved significantly from 4.3 score before implementing the activity to 5.6 $\operatorname{score}(p=.001)$ after implementing it. The results suggest that applying horticultural activities that can stimulate all five senses using natural objects familiar and interesting to children will be effective for sensory development of children.
\end{abstract}

Keywords: attention concentration, pegboard, self-control

\section{Introduction}

Piaget who studied the stages of human development classified ages 7-11 as the concrete operational stage, to which elementary school age children belong. Children in the concrete operational stage perceive things in relation to a specific event or object. In this stage, direct sensory experiences of specifically seeing, hearing, smelling, touching, tasting and feeling events and objects by stimulating the senses are very important (Kim et al., 2003) and significant for education. Humans accept various sensory stimulations from the environment through the sensory organs since birth, systemizing

Received: September 24, 2018, Revised: October 12, 2018, Accepted: October 16, 2018 
and developing physical senses. Such sensory development is expressed as a suitable response as the cerebrum accepts the external environment. Moreover, the senses are represented as adaptive behaviors according to the context due to interpretation, association and integration (Bang, 2013). Flowers and vegetables are known to stimulate sight, touch, smell, and taste, and spraying water in the garden can also increase the auditory effect (Kaplan, 1994). Moreover, horticultural activities stimulate the sight with various shapes and colors of plants, the touch with touching petals and rubbing hands, the smell with fragrances of flowers and fruits, the taste with fruits, and the hearing with listening to the sounds of nature and imitating them in the activities. These horticultural activities stimulating the five senses can provide an environment in the form of multisensory stimulations that can develop emotional stability and sensibility of children (Lee et al., 2011).

Previous studies on horticultural activities stimulating the five senses examined the effects of horticultural therapy stimulating the five senses on the mental functions of schizophrenia patients (Lee, 2007), case of response from bed-ridden patients with severe disabilities toward a horticultural therapy program stimulating the five senses (Lee, 2009), effects of horticultural activities stimulating the five senses on stress reduction of elementary school students (Kim, 2010), and effects of the horticultural therapy program stimulating the five senses on concentration and problem behaviors of children from low-income families (Lee et al., 2011). However, most of them involved partial intervention rather than intervening in the entire program, and none of them was on the improvement of sensory development for each of the five senses even though the program stimulating the five senses was provided every session. Thus, we raised the need for a program that maximizes the effect of stimulating the five senses and develops the senses through intervention in each of the five senses - sight, touch, smell, hearing and taste - for every session of the horticultural program. Therefore, this study was conducted to determine the effects of horticultural activities stimulating the five senses on sensory development of children.

\section{Research Methods}

\section{Subjects}

The subjects of this study were 41 children of the $\mathrm{H}$ regional children's center in D city who agreed to participate in the research after listening to the explanation of research objectives. The control group that did not agree to participate in horticultural activities had 19 students (11 male and 8 female), and their mean age was $9.1 \pm 1.4$. The experimental group that agreed to participate in horticultural activities had 22 students (12 male and 10 female), and their mean age was $9.3 \pm 1.4$.

\section{Tools}

\section{Program design}

This study designed a program with horticultural activities that can stimulate all five senses in each session for sensory development of children. As therapeutic intervention for stimulation of the five senses, vivid colors, various sizes and forms were used to stimulate the sight, and contrasting or equivalent textures were used to stimulate the touch. Sounds of nature on YouTube videos were used to stimulate the hearing, and scents of flowers, plants, fruits and tea were used to stimulate the smell. Moreover, sweet, sour, bitter and salty tastes were used to stimulate the taste, thereby developing the senses (Table 1). 
Table 1. Training program for florist certification in the experimental group

\begin{tabular}{|c|c|c|c|c|c|c|}
\hline \multirow{2}{*}{ Session } & \multirow{2}{*}{ Horticultural activities } & \multicolumn{5}{|c|}{ Five senses } \\
\hline & & Visual & Tactile & Auditory & Olfactory & Taste \\
\hline 1 & $\begin{array}{l}\text { Making collages with } \\
\text { flowers and mosses }\end{array}$ & Reindeer moss & Rip, paste & Water sound & Flower, leaf & Jasmine tea \\
\hline 2 & Making potpourri & $\begin{array}{l}\text { Rosa hybrida, } \\
\quad \text { ribbon }\end{array}$ & Paste, lash & $\begin{array}{l}\text { Grasshopper } \\
\text { sound }\end{array}$ & Potpourri & Chamomile tea \\
\hline 3 & Making tangerine syrup & $\begin{array}{l}\text { Citrus spp., } \\
\text { Salix gracilistyla }\end{array}$ & Insert, paste & Wave sound & Tangerine & $\begin{array}{c}\text { Tangerine, } \\
\text { sugar, corn tea }\end{array}$ \\
\hline 4 & $\begin{array}{l}\text { Flower arrangement } \\
\text { in the cup }\end{array}$ & $\begin{array}{l}\text { Chrysanthemum morifolium, } \\
\text { Limonium sinuatum }\end{array}$ & $\begin{array}{l}\text { Insert, trap, } \\
\text { soak }\end{array}$ & Sound of rain & Flower & Lemon tea \\
\hline 5 & $\begin{array}{l}\text { Flower arrangement } \\
\text { in the Bokjori }\end{array}$ & $\begin{array}{l}\text { Chrysanthemum morifolium, } \\
\text { Freesia hybrida }\end{array}$ & $\begin{array}{l}\text { Insert, cut, } \\
\text { soak }\end{array}$ & Bird sound & Flower & $\begin{array}{l}\text { Chrysanthemum } \\
\text { tea }\end{array}$ \\
\hline 6 & $\begin{array}{l}\text { Making herbal fruit } \\
\text { chocolates }\end{array}$ & $\begin{array}{l}\text { Mentha suaveolens, } \\
\text { chocolate }\end{array}$ & Crack, squeeze & Wave sound & Chocolate, herb & Peppermint tea \\
\hline 7 & Transplanting herbs & $\begin{array}{l}\text { Mentha suaveolens, } \\
\text { ribbon }\end{array}$ & Insert, rub & Cricket sound & Herb & Rosemary tea \\
\hline 8 & $\begin{array}{l}\text { Making collages with } \\
\text { cinnamon and grain }\end{array}$ & $\begin{array}{c}\text { Cinnamomum japonicum, } \\
\text { Glycine max }\end{array}$ & Paste, touch & Grain maracas & Cinnamon & Cinnamon tea \\
\hline 9 & Mandala configuration & $\begin{array}{l}\text { Soap flower, } \\
\text { color pebble }\end{array}$ & Insert, paste & Bird sound & Flower, candy & $\begin{array}{l}\text { Candy, } \\
\text { dandelion tea }\end{array}$ \\
\hline 10 & Making a terrarium & $\begin{array}{l}\text { Hoya carnosa, color sugar, } \\
\text { color sand }\end{array}$ & Insert, touch & $\begin{array}{l}\text { Grasshopper } \\
\text { sound }\end{array}$ & Leaf & $\begin{array}{c}\text { Sugar, } \\
\text { buckwheat tea }\end{array}$ \\
\hline 11 & $\begin{array}{c}\text { Sprouting, flower } \\
\text { decoration with strawberry }\end{array}$ & $\begin{array}{l}\text { Raphanus sativus, } \\
\text { Fragaria grandiflora }\end{array}$ & Sprinkle, trap & Wave sound & Strawberry & $\begin{array}{c}\text { Strawberry } \\
\text { hydrangea tea }\end{array}$ \\
\hline 12 & $\begin{array}{l}\text { Making sandwiches } \\
\text { with sprouts }\end{array}$ & Raphanus sativus & Chop, burr & Sound of rain & Lemon & $\begin{array}{l}\text { Sprout seeds, } \\
\text { lemon }\end{array}$ \\
\hline
\end{tabular}

\section{Program implementation}

This study carried out total 12 sessions of horticultural activities every Wednesday at 2-4 p.m. from January 4 to March 29, 2017. Each session lasted for two hours, and 22 subjects in the experimental group were divided into groups of 12 and 10 , each group carrying out an hour of the activities. The activities took place at a $66 \mathrm{~m}^{2}$ program hall at the children's center, and the program was carried out in three steps: introduction, development and wrap-up. The program was led by a welfare horticultural therapist (Korean Horticultural Therapy Association) with the assistance of one welfare counselor and two trainees (interns).

The following shows a few cases in which horticultural activities provided in Table 1 are carried out. For visual stimulation, various shapes of seeds were used in seeding or making collages, and floral foams were shaped or cut before putting flowers in. For auditory stimulation, the subjects listened to the sounds of grasshoppers, wind in the forest, leaves rustling in the wind, birds, waves, and stream flowing on YouTube. During the activities, they were also to listen to the sounds of shaking soil cement, watering plants, and cutting cinnamon without missing any of the small sounds. For tactile stimulation, the subjects ripped and pasted moss and petals, rubbed herbal leaves, touched pussy willows and soil to compare the textures, such as rough and soft, dry and moist, etc. For olfactory stimulation, the subjects were to smell aromatic plants, soil, bark of a tree, citruses, lemons, cucumber and cinnamon. For gustatory stimulation, the subjects tasted sandwiches made with sprouts they grew themselves, as well as lemons, citruses, cucumber, paprika, cinnamon and 
chrysanthemum tea, after which they shared how they felt about the tastes they experienced.

\section{Evaluation tool}

This study carried out horticultural activities that can stimulate all five senses for sensory development of children, and measured each sense before and after the program in order to prove its effectiveness.

\section{- Visual}

According to the study on the effects of visual stimulation on psychological and physiological changes of human body, visual stimulation of positive forest landscape increases attention recovery (Lee et al., 2014), and accordingly this study measured visual effect with attention. The FAIR (Frankfurter Aufmerksamkeits-InventaR) test of attention was developed by Moosbrugger and Oehlschlaegel in Germany in 1995 and adapted and standardized by Oh (2002). This test can measure selective attention (P), self-control (Q) and sustained attention (C), and it provides results in percentage scale and 9-level criteria by adding the total number of items and line error, omission error, false alarm and error according to the diagram.

\section{- Tactile}

Tactile stimulation increases hand dexterity and spatial cognition of finger positions (Schweizer et al., 2001). Therefore, this study used the Grooved Pegboard (Lafayette instrument, USA, 2003) that measures hand dexterity and visual perception-motor coordination to examine tactile changes. This tool measures the time required to fill up 25 irregular holes with 25 pegs, with children using fewer pegs in the same method as adults and measuring time to fill up the holes in the first and second line of the pegboard with 10 pegs. This study measured the time spent putting 10 pegs using the major and non-major hand of children.

\section{- Auditory}

The test by Kwak (1998) that consists of 10 items in listening and answering questions and 7 items in listening and finding is a test measuring auditory attention. To make measurements in the same conditions before and after the experiment, this study used the form of having the subjects listen to the passages recorded by the welfare horticultural therapist and answer them, with 10 items in listening and answering questions recorded as 1 minute and 41 seconds, and 7 items in listening and finding as 56 seconds.

\section{- Olfactory}

When fragrance ingredients are inhaled, they lead to the brain through odorant binding protein (OBP) in nasal mucosa and olfactory receptor cells (Barkai, 2014). Thus, this study used essential oil extracted from herbal plants that induce fragrance using the olfactory recognition measuring method. The subjects were to inhale lavender, peppermint and rosemary essential oil for 3 seconds at a $3-5 \mathrm{~cm}$ distance from their nose, and then smell total 4 cards (3 cards with lavender, peppermint and rosemary oil, and a card with lemon balm oil as an interference factor), earning one point when they accurately recognized the fragrances.

\section{- Taste}

The taste felt when the substance involved in taste touches the tongue is received by the taste bud. This passes through various delivery routes and is transformed into electrical signals of neurons, creating taste as it is delivered to the brain (Katz et al., 2001). Thus, this study classified four types of substances, such as sweet (sugar), sour (vinegar), bitter (coffee) 
and salty (salt) into three levels of concentration $(0.1 \mathrm{M}, 1 \mathrm{M}, 5 \mathrm{M})$, using 12 cups of solutions containing the four types of substances dissolved in them. The subjects covered their eyes with an eye patch and tasted each solution by putting a cotton swab dabbed with the solution on the tongue mucosa, earning one point when they accurately recognized the taste.

\section{Data analysis}

Test of normality was conducted on the collected data with the Kolmogorov-Smirnov test (K-S test) using IBM SPSS Program (19.0). An independent samples t-test was conducted to test homogeneity of the two groups, and then a paired sample t-test to examine changes before and after horticultural activities within the group.

\section{Results and Discussion}

\section{Normality test of samples}

The Kolmogorov-Smirnov test was used to examine whether the collected data follows normal distribution, and the result showed that selective attention $(p=.744)$, sustained attention $(p=.655)$, and self-control $(p=1.000)$ of sight, non-major hand $(p=1.000)$ and major hand $(p=1.000)$ of touch, auditory concentration $(p=.923)$, olfactory recognition ( $p=.978$ ), and taste recognition ( $p=.642$ ) were all in normal distribution (Table 2). Therefore, the parametric test was used to analyze the results of this study.

\section{Homogeneity pretest of the two groups}

As a preparation for verifying the effects of horticultural activities stimulating the five senses on sensory development, this study conducted a homogeneity pretest of the control group and experimental group. The result showed that there was no significant difference between the two groups in all items, and therefore the two groups were homogeneous. By sense, selective attention ( $p=.279)$, sustained attention ( $p=.583)$, and self-control $(p=.416)$ of sight, non-major hand $(p=.554)$ and major hand $(p=.817)$ of touch, auditory concentration $(p=.500)$, olfactory recognition $(p=.713)$, and taste recognition $(p=.136)$ all did not show a significant difference, and thus the two groups were homogeneous (Table 3 ).

Table 2. Verification of sample normality

\begin{tabular}{|c|c|c|c|c|c|c|c|}
\hline Sense & Item & Unit & $\mathrm{N}$ & M & $\mathrm{SD}$ & $\mathrm{Z}$ & $p$ \\
\hline \multirow{3}{*}{ Visual } & Selective attention & Scale & 41 & 4.2 & 1.6 & 0.680 & $.744^{\mathrm{NS}}$ \\
\hline & Sustained attention & Scale & 41 & 4.1 & 1.6 & 0.733 & $.655^{\mathrm{NS}}$ \\
\hline & Self-control & Scale & 41 & 4.5 & 1.4 & 0.336 & $1.000^{\mathrm{NS}}$ \\
\hline \multirow{2}{*}{ Tactile } & Non-major hand & Second & 41 & 29.1 & 4.9 & 0.344 & $1.000^{\mathrm{NS}}$ \\
\hline & Major hand & Second & 41 & 24.8 & 4.2 & 0.359 & $1.000^{\mathrm{NS}}$ \\
\hline Auditory & Auditory concentration & Score & 41 & 9.7 & 3.5 & 0.550 & $.923^{\mathrm{NS}}$ \\
\hline Olfactory & Olfactory recognition & Score & 41 & 1.1 & 1.1 & 0.474 & $.978^{\mathrm{NS}}$ \\
\hline Taste & Taste recognition & Score & 41 & 4.8 & 2.1 & 0.741 & $.642^{\mathrm{NS}}$ \\
\hline
\end{tabular}

\footnotetext{
${ }^{\mathrm{NS}}$ Non-significant at $p<.05$ by Kolmogorov-Smirnov test.
} 
Table 3. Statistics on homogeneity of control and experimental group before the application of the horticultural activity program

\begin{tabular}{lcccccc}
\hline Sense & Item & Unit & Control & Experimental & $\mathrm{t}$ & $p$ \\
\hline \multirow{3}{*}{ Visual } & Selective attention & Scale & 3.9 & 4.5 & -1.099 & $.279^{\text {NS }}$ \\
& Sustained attention & Scale & 4.0 & 4.3 & -0.554 & $.583^{\text {NS }}$ \\
& Self-control & Scale & 4.7 & 4.3 & -0.822 & $.416^{\text {NS }}$ \\
Tactile & Non-major hand & Second & 28.6 & 29.5 & -0.596 & $.554^{\text {NS }}$ \\
& Major hand & Second & 24.9 & 24.6 & 0.233 & $.817^{\text {NS }}$ \\
Auditory & Auditory concentration & Score & 10.1 & 9.4 & 0.680 & $.500^{\text {NS }}$ \\
\hline Olfactory & Olfactory recognition & Score & 1.1 & 1.2 & -0.371 & $.713^{\text {NS }}$ \\
Taste & Taste recognition & Score & 5.3 & 4.3 & 1.522 & $.136^{\text {NS }}$ \\
\hline
\end{tabular}

${ }^{\mathrm{NS}}$ Non-significant at $p<.05$ by independent $\mathrm{t}$-test.

Table 4. The sensory changes in control and experimental group in pre and post test

\begin{tabular}{|c|c|c|c|c|c|c|c|}
\hline Sense & Group & Item & Unit & Pre & Post & $\mathrm{t}$ & $p$ \\
\hline \multirow{6}{*}{ Visual } & \multirow{3}{*}{ Control } & Selective attention & Scale & 3.9 & 3.8 & 0.417 & $.682^{\mathrm{NS}}$ \\
\hline & & Sustained attention & Scale & 4.0 & 4.3 & -1.242 & $.230^{\mathrm{NS}}$ \\
\hline & & Self-control & Scale & 4.7 & 4.8 & -0.383 & $.706^{\mathrm{NS}}$ \\
\hline & \multirow{3}{*}{ Experimental } & Selective attention & Scale & 4.5 & 7.6 & -8.737 & $.000^{* * *}$ \\
\hline & & Sustained attention & Scale & 4.3 & 7.8 & -9.144 & $.000^{* * *}$ \\
\hline & & Self-control & Scale & 4.3 & 7.3 & -6.263 & $.000^{* * * *}$ \\
\hline \multirow{4}{*}{ Tactile } & \multirow{2}{*}{ Control } & Non-major hand & Second & 28.6 & 28.5 & 0.170 & $.867^{\mathrm{NS}}$ \\
\hline & & Major hand & Second & 24.9 & 25.1 & -0.240 & $.813^{\mathrm{NS}}$ \\
\hline & \multirow{2}{*}{ Experimental } & Non-major hand & Second & 29.6 & 23.2 & 4.758 & $.000^{* * *}$ \\
\hline & & Major hand & Second & 24.6 & 23.3 & 1.372 & $.185^{\mathrm{NS}}$ \\
\hline \multirow{2}{*}{ Auditory } & Control & Auditory concentration & Score & 10.1 & 9.6 & 1.394 & $.180^{\mathrm{NS}}$ \\
\hline & Experimental & Auditory concentration & Score & 9.4 & 12.2 & -3.916 & $.001^{* * *}$ \\
\hline \multirow{2}{*}{ Olfactory } & Control & Olfactory recognition & Score & 1.1 & 1.2 & -0.524 & $.607^{\mathrm{NS}}$ \\
\hline & Experimental & Olfactory recognition & Score & 1.2 & 2.2 & -3.511 & $.002^{* * *}$ \\
\hline \multirow{2}{*}{ Taste } & Control & Taste recognition & Score & 5.3 & 5.5 & -0.593 & $.561^{\mathrm{NS}}$ \\
\hline & Experimental & Taste recognition & Score & 4.3 & 5.6 & -3.710 & $.001^{* * *}$ \\
\hline
\end{tabular}

${ }^{\mathrm{NS}}$ Non-significant, significant at ${ }^{*} p<.05,{ }^{* *} p<.01,{ }^{* * *} p<.001$ by paired t-test.

\section{Pretest-posttest changes within the group}

To determine the effects of horticultural activities stimulating the five senses on sensory development of children, this study measured each of the five senses before and after horticultural activities. Table 4 shows the changes in each sense of the two groups. 


\section{Visual change}

Visual changes before and after horticultural activities applying visual stimulation are as follows. There was no significant change in all items of the control group in terms of sight in the FAIR test: selective attention changed from Level 3.9 to 3.8 ( $p=.682$ ), sustained attention from Level 4.0 to 4.3 ( $p=.230)$, and self-control from Level 4.7 to 4.8 ( $p=.706)$. On the other hand, the experimental group showed a significant improvement in the FAIR attention test: selective attention changed from Level 4.5 to 7.6 ( $p=.000)$, sustained attention from Level 4.3 to 7.8 ( $p=.000)$, and self-control from Level 4.3 to 7.3 after the program $(p=.000)$. Consistent with the result that only the visual stimulation of green plants increases attention by activating alpha and theta waves after horticultural activities (Kim, 2007), this study also found that green plants, various colors of flowers and moss, colored stones, sand and sugar used to stimulate the sight enabled the subjects to distinguish color differences and stimulated the sight with unique colors of the materials, thereby increasing children's visual attention and effective on sensory development. Color is within the spaces or objects that we encounter and thus has a great emotional effect, and can particularly increase attention (Jeong, 2009).

\section{Tactile change}

Tactile changes before and after horticultural activities applying tactile stimulation are as follows. In the Grooved Pegboard test by the control group, non-major hand changed from 28.6 seconds to 28.5 seconds ( $p=.867$ ), and major hand changed from 24.9 seconds to 25.1 seconds $(p=.813)$ without a significant difference. On the other hand, for the experimental group, non-major hand changed from 29.6 seconds to 23.2 seconds $(p=.000)$ with a significant increase after the program, whereas major hand did not show a significant change from 24.6 seconds to 23.3 seconds ( $p=.185$ ). Various plants are effective in sensory stimulation and touching various forms of plants is suitable for stimulating touch (Yun, 2007). Horticultural activities stimulating touch by rubbing with palms, cutting, pegging and tying were effective for touch sensory development of non-major hand and hand dexterity. The result of sensory development excluding the major hand in touch showed that various tactile stimulations were more effective on sensory development of non-major hand that is not often used in daily life than the frequently used major hand.

\section{Auditory change}

Auditory changes before and after horticultural activities applying auditory stimulation are as follows. In the 10 items of listening to questions and answering and the 7 items of listening and finding by Kwak (1998) to measure the auditory development of the control group, the result did not show a significant difference from 10.1 points to 9.6 points $(p=.180)$. On the other hand, the experimental group showed a significant increase from 9.4 points to 12.2 points ( $p=.001)$ after the program. Consistent with the result of auditory stimulation on children with the sounds of nature, their selective attention, sustained attention and self-control increased, thereby improving attention in general (Kwak, 2006), this study also carried out an activity distinguishing the sound of birds from the sounds of nature on YouTube. The result led to the development of auditory sense as the subjects could listen attentively to the sounds of nature and distinguish them in comparing the slight difference in sounds.

\section{Olfactory change}

Olfactory changes before and after horticultural activities applying olfactory stimulation are as follows. In the olfactory recognition test to measure olfactory development of the control group, there was no significant change from 1.1 points to 1.2 points $(p=.607)$. On the other hand, the experimental group showed a significant increase in the olfactory recognition test from 4.3 points to 5.6 points $(p=.001)$ after the program. Consistent with the previous study that olfactory stimulation 
increased selective attention, sustained attention, self-control and overall attention by activating and awakening the brain (Baek, 2009), this study also had the subjects smell aromatic flowers, cypress, herbs, citrus, lemon, cinnamon and bark, which stimulated their brains and improved their olfactory attention by bringing memories back in association with the smell, guessing and comparing the smells.

\section{Taste change}

Taste changes before and after horticultural activities applying gustatory stimulation are as follows. In the taste recognition test to measure the taste development of the control group, there was no significant change in all items from 5.3 points to 5.5 points $(p=.561)$. On the other hand, the experimental group showed a significant increase in the taste recognition test from 4.3 points to 5.6 points $(p=.001)$ after the program. The result of this study, which increased taste attention by focusing on the feeling of taste and unique experience through comparison of citrus and lemon and tasting of cinnamon and colored sugar, is consistent with the study that interest and active participation through taste experience induced development of taste attention (Lee, 2016).

Like the results obtained by Ma (2009) through horticultural activities for persons with intellectual disabilities, this study also discovered that horticultural activities naturally provide clues that represent shapes, sizes, colors and directions that stimulate visual perception. In other words, green plants, vivid colors of flowers and moss, colored stones, sand and sugar used to stimulate the sight enabled the subjects to distinguish color differences and stimulated the sight with unique colors of the materials, thereby improving children's visual attention and sensory development. In particular, there was a horticultural activity of comparing the subtle differences in sounds through the sounds of nature on YouTube in each step of the situation. The subjects listened to the sounds as instructed by the therapist to increase completeness of the result, which stimulated their hearing and improved auditory concentration and sensory development. Moreover, closing the eyes and guessing the letters carved with soil using only the touch of hand provided the subjects with a chance to feel and recognize the letters using only the touch of their fingers. This increased dexterity of the tip of the hands and the curiosity was also effective on development of children's tactile sense. Moreover, the activity of smelling various materials such as flowers, herbs, cinnamon and bark provided the diversity of fragrances for children that are limited to the types of smell, which was effective in improving children's olfactory sense and olfactory concentration. The fact that there was a significant change in taste recognition after the activities indicated that children could accurately recognize different tastes in association with language after tasting various things and talking about them in relation to personal memories of the taste. Various gustatory stimulation activities improved language development and taste recognition, which led to sensory development.

Senses by external and physical stimulations such as sight or hearing significantly affect human behavior patterns (Kim et al., 1998). Thus, stimulating the five senses with the shapes, scents, colors and textures of various plants will contribute to children's sensory and behavioral development. Therefore, using horticultural activities that stimulate all five senses in the educational setting with natural objects that are familiar and interesting to children will be effective for sensory development of children.

\section{Conclusion}

To determine the effects of horticultural activities stimulating the five senses on sensory development of children, this study implemented total 12 sessions of the program once a week from January 4 to March 29, 2017 with 22 children at the 
$\mathrm{H}$ regional children's center located in D city. The control group did not show a significant change in attention of each sense after the program, whereas the experimental group showed a significant improvement in all senses except for the major hand in the pegboard test. In visual measurement, selective attention increased significantly from Level 4.5 to 7.6 ( $p=.000)$, sustained attention from Level 4.3 to 7.8 ( $p=.000)$, and self-control from Level 4.3 to 7.3 ( $p=.000)$ after the program. In tactile measurement, the non-major hand increased significantly from 29.6 seconds to 23.2 ( $p=.000$ ), but the major hand did not show a significant change from 24.6 seconds to 23.3 seconds $(p=.185)$. There was a significant improvement in the auditory sense after the program from 9.4 points to 12.2 points ( $p=.001$ ), olfactory sense from 1.2 points to 2.2 points ( $p=.002$ ), and taste sense from 4.3 points to 5.6 points $(p=.001)$. The results above prove that applying horticultural activities that can stimulate all five senses using natural objects familiar and interesting to children to the educational settings will be effective for sensory development of children.

\section{References}

Baek, S.M. 2009. The effect of rosemary aroma oil on the concentration of the elementary school students. Master's thesis, Kyonggi University, Suwon, Korea.

Bang, J.I. 2013. The effects of music therapy centered on sensory integration on the sensory development and attention. Master's thesis, Kosin University, Busan, Korea.

Barkai, E. 2014. Neural mechanisms of odor rule learning. Prog. Brain Res. 208:253-274. DOI:10.1016/B978-0-444-63350-7.00010-3

Jeong, D.C. 2009. A research on the color recognition of high graders in elementary school. J. Art Educ. 25:125-162. Retrieved from http://www.keaea.org/

Kaplan, M. 1994. Use of sensory stimulation with Alzheimer patients in a garden setting. In: J. Flagler and R.P. Poincelot (Eds.), People-plant relationships: Setting research priorities. Binghamton, NY: Hayworth press, Inc.

Katz, D.B., S.A. Simon, and M.A. Nicolelis. 2001. Dynamic and multimodal responses of gustatory cortical neurons in awake rats. J. Neurosci. 21(12):4478-4489.

Kim, J.H., G.M. Lee, and S.D. Kwon. 2003 Educational Psychology. Seoul, Korea: Yangseowon.

Kim, J.Y. 2007. The effect of meditation training program on children's emotional stability and attentiveness. Master's thesis, Seoul National University of Education, Seoul, Korea.

Kim, M.J. 2010. Effect of five senses-stimulation horticultural activity on the stress relief of elementary school children. Master's thesis, Seoul National University of Education, Seoul, Korea.

Kim, N.G., J.H. Kim, and C.K. You. 1998. A study on visual and auditory emotion under color and music stimuli. J. Korean Soc. Med. Biomed. Eng. 19(5):539-546.

Kwak, S.D. 2006. The effects of natural sound meditation music on the improvement of the elementary school student's attentions. Master's thesis, Changwon University, Changwon, Korea.

Kwak, S.Y. 1998. A study on development of attention test instrument and its validity. Master's thesis, Sookmyung Women's University, Seoul, Korea.

Lee, E.J. 2016. Study on conception guidance plan for the subject of art through the sense of smell and taste experiences. Master's thesis, Korea National University of Education. Cheongju, Korea.

Lee, H.R. 2007. Effect of five senses stimulating horticultural therapy on the mental social function of schizophrenic patients. Master's thesis, Daegu Catholic University, Daegu, Korea.

Lee, J.H. 2009. A case study of the response to severe bed ridden disabilities applied horticultural therapy program of stimulating five senses. Master's thesis, Dankook University, Cheonan, Korea.

Lee, P.R., I.J. Han, and C.G. Kim. 2011. Effect of five sence-stimulation horticultural activity program on the attention ability and juvenile delinquency in children with low-income families. J. Korean Soc. People Plants Environ. 14(6):331-336. 
Lee, Y.H., C.W. Park, and J.J. Kim. 2014. Effects of visual stimulus with forest scenery types on psychological and physiological status of human. J. Korean Soc. People Plants Environ. 17(1):65-71.

Ma, J.M. 2009. Effects of the horticultural therapeutic program on the selective attentiveness and attention sustaining behavior children with mild HR. J. Psychol. Behav. 1(2):43-69. Retrieved from http://www.kpsa.org/

Oh, H.S. 2002. FAIR attention test. Seoul, Korea: Jungang Jeokseong Press.

Schweizer, R., C. Braun, C. Fromm, A. Wilms, and N. Birbaumer. 2001. The distribution of mislocalizations across fingers demonstrates training-induced neuroplastic changes in somatosensory cortex. Exp. Brain Res. 139(4):435-442.

Yun, S.Y. 2007. Effects of the application of horticultural therapy based on Pincus' theory of rehabilitation practice on demented elder'daily activity functions and physiological changes. Doctoral dissertation, Daegu Catholic University, Daegu, Korea. 